\title{
CHRONIC MONTEGGIA FRACTURE-DISLOCATION IN CHILDREN SURGICAL STRATEGY AND RESULTS
}

\section{FRATURA-LUXAÇÃO DE MONTEGGIIA CRÔNICA EM CRIANÇAS: ESTRATÉGIA CIRÚRGICA E RESULTADOS}

\author{
Jamil Faissal Soni ${ }^{1,2}$, Weverley Rubele Valenza ${ }^{1,2}$, Carolina Umeta Matsunaga ${ }^{2}$, anna Carolina Pavelec Costa ${ }^{2}$, \\ FERNANDO FERRAZ FARIA ${ }^{1,2}$
}

1. Hospital do Trabalhador, Curitiba, PR, Brazil.

2. Hospital Universitário Cajuru, Pontifícia Universidade Católica do Paraná, Curitiba, PR, Brazil.

\section{ABSTRACT}

Objective: To report surgical techniques and results in the treatment of chronic Monteggia fracture-dislocation in children. Methods: Six pediatric patients who had undergone a procedure involving the following 6 crucial surgical steps were retrospectively evaluated: 1- extended lateral approach, 2- fibrotic removal, 3-proximal ulnar osteotomy, 4- reduction of the radial head and transcapitellar temporary fixation, 5- ulnar fixation with a straight plate shaped according to the deformity generated by temporary fixation, and 6- transcapitellar Kirschner wire removal. Results: Four patients were women, and four showed the right-sided compromise. The mean age of patients was 8 years, and the minimum follow-up period was 12 months. The mean time from the onset of fracture to treatment was 6 months. Six patients underwent complete flexo/extension, and one patient had a complete prono-supination. In four patients, we observed loss of pronation (by $10^{\circ}$ in two, $15^{\circ}$ in one, and $20^{\circ}$ in one), and one patient had $15^{\circ}$ decrease in supination. We did not observe any redislocation of the radial head in the follow-up evaluation. No complications were observed; the only complaint was salience of the ulnar plate. Conclusions: Our results demonstrated an effective option for the treatment of chronic Monteggia fracture-dislocation in children, even with a small study sample, following the presented technical and surgical strategies. Level of evidence IV, Therapeutic Studies.

Keywords: Monteggia fracture/pathology, Monteggia fracture/ surgery, Monteggia fracture/complications.

\section{RESUMO}

Objetivo: Relatar a técnica cirúrgica e os resultados no tratamento da fratura-luxação de Monteggia crônica nas crianças. Métodos: Análise retrospectiva de seis pacientes submetidos à técnica com seis passos cirúrgicos, a saber: acesso único lateral estendido para o bordo lateral da ulna; capsulotomia e retirada da fibrose e do tecido interposto; osteotomia proximal transversa da ulna; redução da cabeça radial no capítulo e fixação temporária transcapitelar; fixação da ulna com placa reta moldada a deformidade gerada da ulna; retirada do fio de Kirschnner transcapitelar. Resultados: Quatro pacientes eram do sexo feminino, e em quatro o lado direito foi o acometido. 0 seguimento mínimo foi de 12 meses, e o tempo médio entre a fratura e o tratamento foi de 6 meses. Os seis pacientes obtiveram flexo/extensão completa; em quatro deles, foi observada perda da pronação (dois $10^{\circ}$, um $15^{\circ}$ e um $20^{\circ}$ ) e um paciente teve diminuição de $15^{\circ}$ da supinação. Em todos os pacientes, foi obtida redução da cabeça do rádio sem reluxação até o seguimento avaliado. Conclusões: Mesmo considerando uma pequena amostra, nossos resultados, pela técnica e pelas estratégias cirúrgicas apresentadas, demonstraram opção eficaz no tratamento da fratura-luxação de Monteggia crônica em crianças. Nível de evidência IV, estudo do tipo terapêutico.

Descritores: Fratura de Monteggia/patologia. Fratura de Monteggia/ cirurgia. Fratura de Monteggia/complicações.

Citation: Valenza WR, Matsunaga CU, Faria FF, Costa ACP, Soni JF. Chronic monteggia fracture-dislocation in children - surgical strategy and results. Acta Ortop Bras. [online]. 2019;27(5):244-7. Available from URL: http://www.scielo.br/aob.

\section{INTRODUCTION}

Monteggia fracture-dislocation was described by Giovanni Batista Monteggia in 1814, as an ulnar fracture, usually in the proximal edge associated to a dissociation of the proximal radioulnar joint, with consequent dislocation of the radiocapitellar joint (dislocation of the head). ${ }^{1}$ Bado has proposed a classification that helps on a better understanding of the injury and its correct management, describing the mechanisms of the fracture, its displacement and angulation presented on a ulnar fracture and the direction of the dislocations deviation of the radial head ${ }^{2}$ and the direction of the radial head dislocation.

Monteggia fracture-dislocation is usually seen between 4yrs to $10 y r s$, uncommonly incident (it's a rare injury), corresponding to less than $1 \%$ of all pediatric fractures. ${ }^{3}$

All authors declare no potential conflict of interest related to this article.

This work was performed at the Hospital do Trabalhador, Curitiba, PR, Brazil.

Correspondence: Av. Rep. Argentina, 4406, Novo Mundo, Curitiba, PR, Brazil. 81050-000. weverleyvalenza@yahoo.com 
Despite its rarity, its greatest importance lies in the fact that the diagnosis is not correctly carried out, being missed in up to $50 \%$ of cases, especially in cases of radial head dislocation associated with a plastic deformation or a greenstick fracture of the ulna. ${ }^{4,5}$ Another situation that increases the number of cases of chronic Monteggia is the loss of the initial reduction, what may occur in $20 \%$ of patients. ${ }^{6}$

Due to inaccurate diagnosis of the initial trauma, neglected Monteggia fracture-dislocation may proceed with pain, mobility limitations loss of motion (especially flexion and supination), elbow stiffness, deformity, loss of strength, late neuropathy and osteoarthritis. ${ }^{7}$

Several surgical techniques have been described to approach and correct chronic Monteggia fracture dislocation, such as: opened reduction and reconstruction of the annular ligament ${ }^{8,9}$, opened reduction and ulnar osteotomy ${ }^{10-13}$, ulnar osteotomy and progressive correction with external fixator ${ }^{14,15}$, radial osteotomy ${ }^{16-17}$ and radial head excision ${ }^{18,19}$. Usually, the described series are composed by small samples with no consensus or standardization on the most appropriate treatment.

Our goal is to demonstrate the clinical and radiographic results of our standardized surgical strategy for chronic Monteggia fracture-dislocation type I of Bado in children.

\section{MATERIALS AND METHODS}

The study was approved by the Research Ethics Committee (CAAE 55157016.9.0000.5225), according to Resolution 196/96 e 251/97, of the National Health Council.

A retrospective analysis was performed on six pediatric patients presenting Monteggia fracture-dislocation type I of Bado by the authors' group of Pedriatric Orthopedics. The patients were submitted to the same standardized surgical technique (6 steps), with mean follow-up of 3 years. In the post- operative clinical evaluation we accessed the presence of pain and flexo-extension or prono-supination loss of movement. The congruency of the radial epiphysis with the capitellum on the $\mathrm{x}$-ray exams at the last follow-up lateral radiography at the last follow-up was considered adequated. We included in our study patients admitted between 2006 and 2015 according to the inclusion ? criteria: children or teenagers less than to 16 years presenting Monteggia fracture-dislocation. Patients with less than six months of follow up, older than 16 yrs, congenital dislocation of the radial head diagnosis, chronic dislocation / teratological radial head associated with syndromes and patients who had records with incomplete data were excluded from the study.

All patients underwent to the same surgical strategy of 6 basic stages, as described below:

- Single approach side extended to the lateral edge of the ulna (Figure 1)

- Radiocapitellar and humeroulnar capsutolomy, with fibrosis removal and tissue interposition with tissue interposition and fibrosis removal.

- Ulnar transverse proximal osteotomy

- Radial head anatomic reduction in the capitullum and temporary transcapitellar fixation from posterior to anterior with Kirschnner $2 \mathrm{~mm}$ wire(Figure 2).

- Ulnar fixation with straight plate of $3,5 \mathrm{~mm}$ or $2,7 \mathrm{~mm}$ shaped according to the deformity generated in the ulna after the beginning of transcapitellar temporary fixation, usually in dorsal deviation and lengthening (Figure 3)

- Transcapitellar Kirschnner wire removal with flexo-extension and prono-supination stability test.

This post-operative procedure was followed in all cases, keeping immobilization by an elbow cast splint in neutral position for 4 weeks.

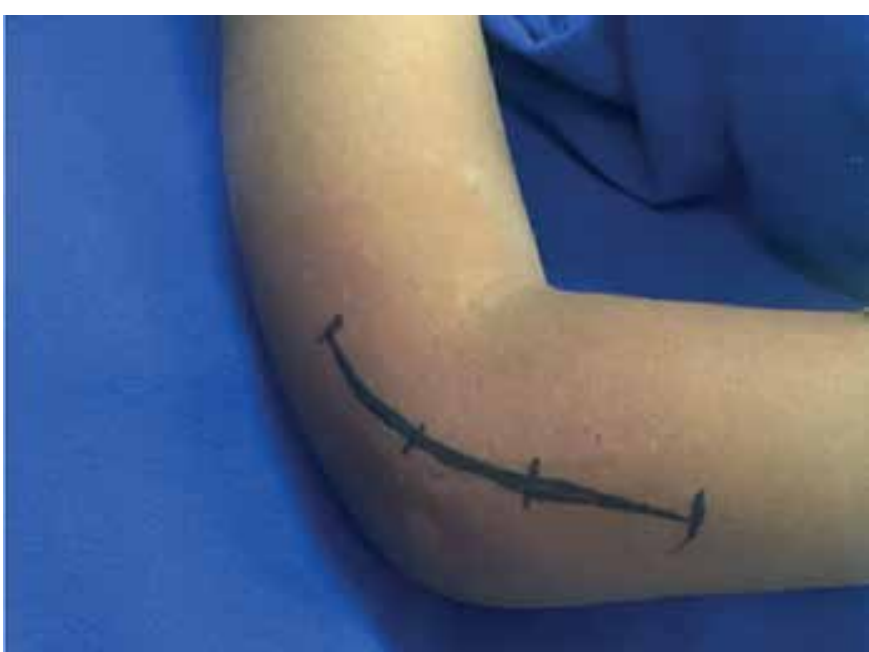

Figure 1. Single approach side extended to the lateral edge of the ulna.

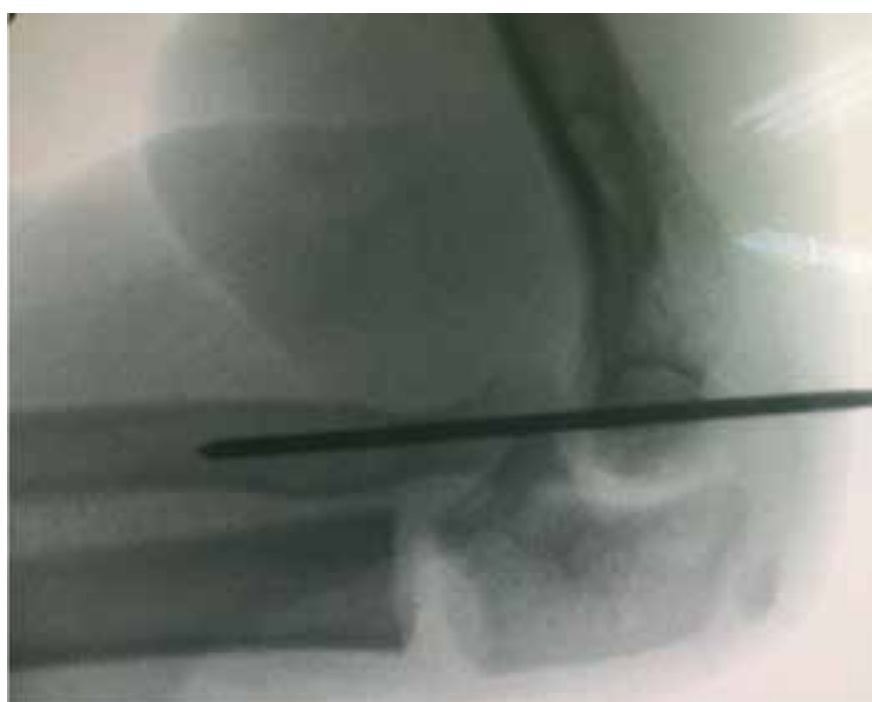

Figure 2. Radial head anatomic reduction in the capitullum and temporary transcapittellar fixation from posterior to anterior with Kirschnner $2 \mathrm{~mm}$ wire.

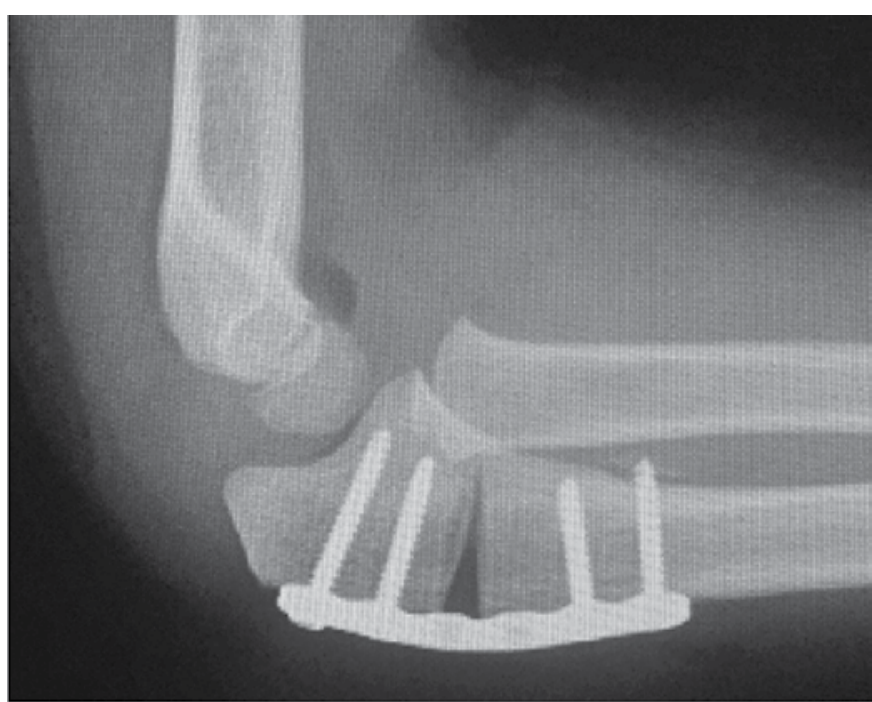

Figure 3. Ulnar Fixation with straight plate of $3,5 \mathrm{~mm}$ or $2,7 \mathrm{~mm}$ shaped according to the deformity generated in the ulna after the beginning of transcapitellar temporary fixation, usually in dorsal deviation and lengthening. 


\section{RESULTS}

The sample was based on the analysis of clinic and radiographic treatment results of 4 males and 2 females. Three fractures were on the right side. The mean age of the patients included in the study was 8 yrs and 1 month and the minimum follow-up was 12 months. Five of the six patients were treated with primary cast (Table 1). Two of them underwent to closed reduction under general anesthesia. The other three patients were also submitted to immobilization with cast without reduction (diagnosis of ulnar fracture, radial head dislocation was missed) and 1 patient had no primary treatment due to lack of diagnosis. The mean time between the trauma and the proposed surgical treatment was 6 months.

After the proposed treatment all the 6 patients showed complete flexo-extension of the elbow joint. Four of the children involved in the study presented decrease in pronation and 1 patient presented limitation on supination. Limitation on pronation of $20^{\circ}$ was identified in 1 patient, $15^{\circ}$ in another, and $10^{\circ}$ in two patients. One patient presented decrease in supination of $15^{\circ}$. All patients maintained the reduction of the radial head at the follow-up radiography, showing no evidence of redislocation (Figure 4 and 5). We have not found major postoperative complications. The only complaint reported by all patients was the salience of plate and screws used for ulnar fixation. All patients had the removal of the osteosynthesis plate after the bone healing (Table 2).

\section{DISCUSSION}

Chronic Monteggia fracture-dislocation may occur after a missed fracture dislocation, as well as after an injury where there was loss of the primary reduction. We find no consensus in literature defining the time to consider it as chronic injury, so the most accepted period is after four weeks ${ }^{5,20}$.

Table 1. Demographic data.

\begin{tabular}{|c|c|c|c|c|c|c|}
\hline Pcte & Gender & Age & Side & Primary cast & \begin{tabular}{|l|} 
Time up to \\
diagnosis
\end{tabular} & Follow-up \\
\hline J.G.C & $\mathrm{M}$ & $3 a 6 m$ & $\mathrm{R}$ & No & 24 Months & 4 Years \\
\hline J.G.R & $M$ & $6 \mathrm{a} 2 \mathrm{~m}$ & $L$ & Yes (missed) & 3 Months & 2 Years \\
\hline L.C.S & $\mathrm{F}$ & $7 \mathrm{a} 1 \mathrm{~m}$ & $\mathrm{R}$ & Yes (missed) & 6 Months & 6 Years \\
\hline B.C.C. & M & $8 \mathrm{a} 5 \mathrm{~m}$ & $\mathrm{R}$ & $\begin{array}{c}\text { Yes } \\
\text { (bad reduction) }\end{array}$ & 3 Months & 1 Year \\
\hline M.C.S & $F$ & $9 a 8 m$ & L & $\begin{array}{c}\text { Yes } \\
\text { (bad reduction) }\end{array}$ & 4 Months & 5 Years \\
\hline R.R.P & $\mathrm{M}$ & $14 \mathrm{a} 1 \mathrm{~m}$ & $\mathrm{~L}$ & Yes (missed) & 1 Month & 1 Year \\
\hline Media & - n--- & $8 \mathrm{a} 1 \mathrm{~m}$ & $+\cdots$ & - --- & 6.8 Months & 3 Years \\
\hline
\end{tabular}

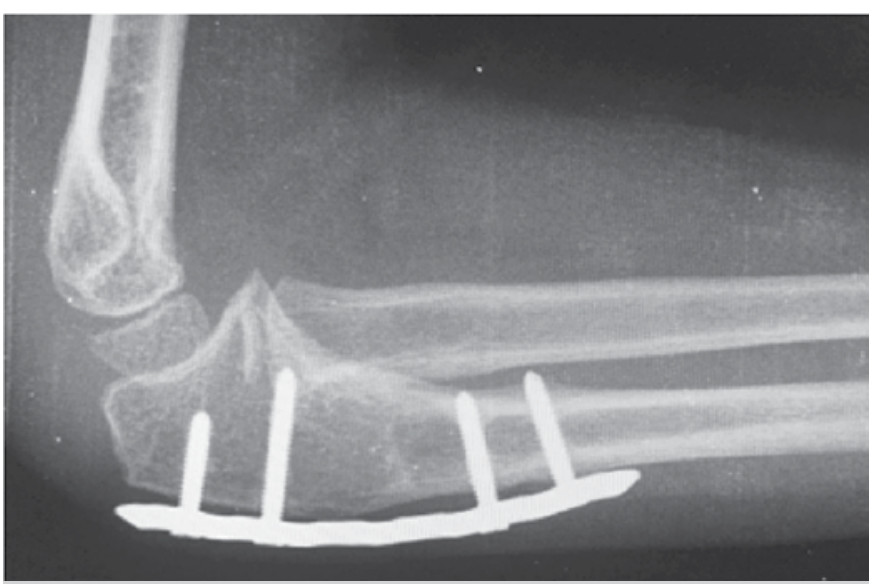

Figure 4. Post-operative 6 month lateral radiography after correction of chronic Monteggia fracture-dislocation.

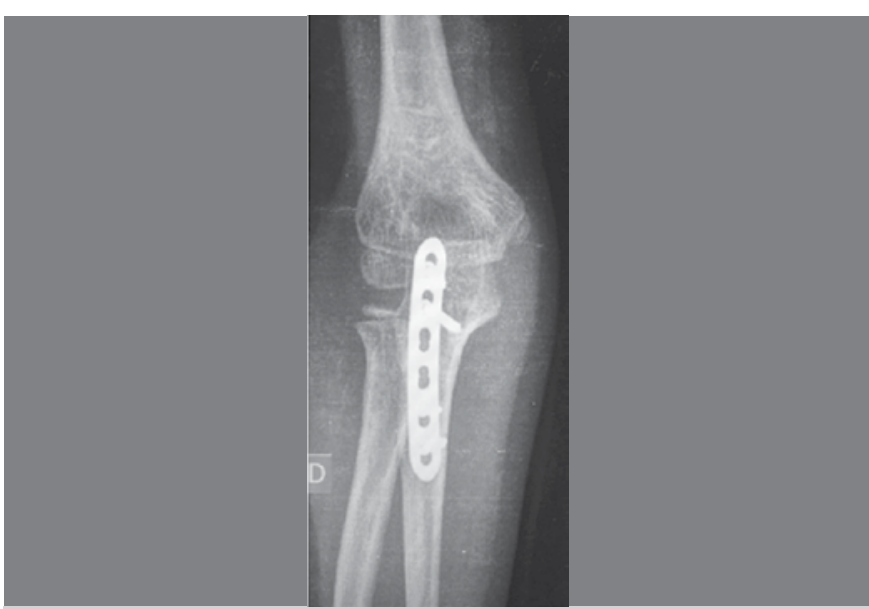

Figure 5. Post-operative 6 month lateral radiography after correction of chronic Monteggia fracture-dislocation.

\begin{tabular}{|c|c|c|c|c|c|c|}
\hline Pcte & $\begin{array}{c}\text { Reduction of } \\
\text { radial head }\end{array}$ & $\begin{array}{l}\text { Prono/ } \\
\text { supina }\end{array}$ & $\begin{array}{l}\text { Flexo/ } \\
\text { extent }\end{array}$ & Complications & \begin{tabular}{|c} 
Plate \\
salience
\end{tabular} & Satisfaction \\
\hline J.G.C & Yes & $90 / 0 / 90$ & $0 / 140$ & No & Yes & Yes \\
\hline J.G.R & Yes & $80 / 0 / 90$ & $0 / 140$ & No & Yes & Yes \\
\hline L.C.S & Yes & $90 / 0 / 75$ & $0 / 140$ & No & Yes & Yes \\
\hline B.C.C. & Yes & $80 / 0 / 90$ & $0 / 140$ & No & Yes & Yes \\
\hline M.C.S & Yes & $70 / 0 / 90$ & $0 / 140$ & No & Yes & Yes \\
\hline R.R.P & Yes & $75 / 0 / 90$ & $0 / 140$ & No & Yes & Yes \\
\hline
\end{tabular}

As the result of the evolution of the lesion, the patient may present pain, joint mobility limitation, elbow stiffness, deformity, and loss of strength, late neuropathy and osteoarthritis. Surgical treatment for correction is indicated to prevent further complications. ${ }^{7}$

The most important point to obtain radial head reduction is to create the ulnar deformity and lengthening and to achieve the consequent maintenance of radialcapitellar congruence. The created deformity was in the opposite direction to the radial head dislocation. ${ }^{12,13}$

Hirayama and cols ${ }^{21}$ and Inoue and cols ${ }^{12}$, showed better results, lower index of re-dislocation and better mobility, when hipper-corrected the ulna post-osteotomy, compared to a simple ulnar osteotomy. We agree with the literature that the ulna is the key to radial head reduction. Our strategy of treatment after the removal of joint fibrosis is to perform ulnar transverse osteotomy and to reduce radial head by temporarily fixing it with Kirschnner $2,0 \mathrm{~mm}$ wire in the capitullum. This way it is achieved an ulnar lengthening and the necessary dorsal deviation to post reduction stability.

Ulnar fixation can be performed with flexible intramedullary rods or Kirschnner wires. In some situations, this fixation can promote the correction or rectification of deformity created on the ulna Another option is the stabilization with external fixation, having the advantage to make any adjustments during treatment. However, a common disadvantage is the infection in the path of pins and the inconvenience for the patient, making it difficult to tolerate. ${ }^{14-15}$ Nowadays, the most used method of fixation is by plate and screws. This implant provides greater stability with less loss on the obtained correction. Another advantage is that the plate may be shaped adapting to the ulnar position..$^{10,19-23}$

In our series we routinely fixed the ulna with plate and screws, shaping the plate to fit to the ulnar position (elongated and dorsal angulations). After the reduction, it was performed a temporary transcapitellar fixation, as proposed by Bae. ${ }^{7}$ After the ulnar stabilization by plate and screws we removed the temporary fixation and test the stability. 
It should be avoided the fixation with transcapitellar wire to add stability during the postoperative period, since it is related to a common limitation on range of motion, especially of prono-supination, besides the risk of intrarticular broken of this wire. In all our cases such fixation was used temporarily.

It is a controversial subject in literature if the annular ligament must or not be reconstructed. Rahbek and cols in their study ${ }^{11}$, reconstructed the ligament in 10 patients and did not do it in six patients, having no difference on the final result. In our sample we did not reconstructed the annular ligament in any of the six treated patients.

As a standard postoperative pattern we chose to immobilize with braquiopalmar splint cast in neutral position for four weeks, avoiding supination, because the greatest functional loss described is from pronation. Our results confirm this trend, despite the loss of pronation of only $10^{\circ}$ in 2 patients, $15^{\circ}$ and $20^{\circ}$ in 2 other patients.

Another important aspect not yet well determined is the time limit to treat aiming to reduce chronic Monteggia fracture-dislocation. Several authors propose the time limit of two, three, four and up to seven years. Other authors consider that the most important fact, despite the time of dislocation to the treatment, would be if the radial head and/or the capitullum would be deformed. None of our patients presented radial head deformity, and in our opinion these amendments could lead to poor results, due to new dislocation, mobility limitation or post-operative pain. 8,17,21,24-26

The complications described in the literature are loss of reduction (re-dislocation), radioulnar synostosis, nerve damage, limitations of flexo-extension and prono-supination. In our series we did not observe any case of re-dislocation of the radial head. Regarding the range of the movement we observed limitation of pronation in four patients (discussed above), the supination $\left(15^{\circ}\right)$ in a patient who did not change the ability to manage daily activities. We have not observed any redislocation of radial head in the accessed follow-up, as well as no other complication as the ones described in the literature. All our patients have reported a mild discomfort caused by the plate, matter solved after its removal.

A small number of cases could be seen as a limitation to our study, but that can be justified partially by the rarity of the presented injury.

\section{CONCLUSION}

The surgical strategy based on the 6 demonstrated steps aiming the reduction and stability of radial head by the capitullum, demonstrating to be applicable on planning and surgically correct chronic Monteggia fracture dislocation in children.

AUTHORS' CONTRIBUTIONS: Each author individually and significantly contributed to the development of this article. WRV (0000-0001-7358-819X)* study design, manuscript drafting, review and critical analysis of the data, besides the execution of surgeries, data analysis, and statistical analysis; CUM (0000-0001-9921-3337)*: study design, manuscript drafting and review, survey and data analysis, and statistical analysis; JFS (0000-0002-9448-7352)*: execution of surgeries, manuscript review, data analysis, and final approval of the manuscript to be published; FFF (0000-0001-6163-5147) ${ }^{\star}$ : execution of surgeries and manuscript drafting and review; ACCP (0000-0003-1055-9601)*: execution of surgeries and final approval of the manuscript to be published *ORCID (Open Researcher and Contributor ID).

\section{REFERENCES}

1. Monteggia GB, editor. Instituzioni Chirurgiches 2nd Vol 5. Milan, Italy: Maspero; 1814.

2. Bado JL. The Monteggia lesion. Clin OrthopRelat Res. 1967;(50):71-86.

3. Kay RM, Skaggs DL. The pediatric Monteggia fracture. Am J Orthop Belle Mead NJ. 1998;27(9):606-9.

4. Gleeson AP, Beattie TF. Monteggia fracture-dislocation in children. Emerg Med J. 1994;11(3):192-4.

5. Goyal T, Arora SS, Banerjee S, Kandwal P. Neglected Monteggia fracture dislocations in children: a systematic review. J Pediatr Orthop Part B. 2015;24(3):191-9.

6. Ramski DE, Hennrikus WP, Bae DS, Baldwin KD, Patel NM, Waters PM, et al. Pediatric monteggia fractures: a multicenter examination of treatment strategy and early clinical and radiographic results. J Pediatr Orthop. 2015;35(2):115-20.

7. Bae DS. Successful Strategies for Managing Monteggia Injuries. J Pediatr Orthop. 2016;36 Suppl 1:S67-70.

8. Gyr BM, Stevens PM, Smith JT. Chronic Monteggia fractures in children: outcome after treatment with the Bell-Tawse procedure. J Pediatr Orthop Part B. 2004;13(6):402-6.

9. Eygendaal D, Hillen RJ. Open reduction and corrective ulnar osteotomy for missed radial head dislocations in children. Strateg Trauma Limb Reconstr. 2007;2(1):31-4

10. Belangero WD, Livani B, Zogaib RK. Treatment of chronic radial head dislocations in children. Int Orthop. 2007;31(2):151-4.

11. Rahbek O, Deutch SR, Kold S, Søjbjerg JO, Møller-Madsen B. Long-term outcome after ulnar osteotomy for missed Monteggia fracture dislocation in children. $J$ Child Orthop. 2011;5(6):449-57.

12. Inoue G, Shionoya K. Corrective ulnar osteotomy for malunited anterior Monteggia lesions in children. 12 patients followed for 1-12 years. Acta Orthop Scand. 1998;69(1):73-6.

13. Nakamura K, Hirachi K, Uchiyama S, Takahara M, Minami A, Imaeda T, et al. Long-term clinical and radiographic outcomes after open reduction for missed Monteggia fracture-dislocations in children. J Bone Joint Surg Am. 2009;91(6): 1394-404.

14. Hasler CC, Von Laer L, Hell AK. Open reduction, ulnar osteotomy and external fixation for chronic anterior dislocation of the head of the radius. J Bone Joint Surg Br. 2005;87(1):88-94

15. Lu X, Kun Wang Y, Zhang J, Zhu Z, Guo Y, Lu M. Management of missed Monteggia fractures with ulnar osteotomy, open reduction, and dual-socket external fixation. J Pediatr Orthop. 2013;33(4):398-402.

16. Horii E, Nakamura R, Koh S, Inagaki H, Yajima H, Nakao E. Surgical treatment for chronic radial head dislocation. J Bone Joint Surg Am. 2002;84(7):1183-8.

17. Stoll TM, Willis RB, Paterson DC. Treatment of the missed Monteggia fracture in the child. J Bone Joint Surg Br. 1992;74(3):436-40.

18. Tajima T, Yoshizu T. Treatment of long-standing dislocation of the radial head in neglected Monteggia fractures. J Hand Surg. 1995;20(3 Pt 2):S91-4.

19. Degreef I, De Smet L. Missed radial head dislocations in children associated with ulnar deformation: treatment by open reduction and ulnar osteotomy. $J$ Orthop Trauma. 2004;18(6):375-8.

20. Bhaskar A. Missed Monteggia fracture in children: Is annular ligament reconstruction always required? Indian J Orthop. 2009;43(4):389.

21. Hirayama T, Takemitsu Y, Yagihara K, Mikita A. Operation for chronic dislocation of the radial head in children. Reduction by osteotomy of the ulna. J Bone Joint Surg Br. 1987;69(4):639-42.

22. Lädermann A, Ceroni D, Lefèvre $Y$, De Rosa V, De Coulon G, Kaelin A Surgical treatment of missed Monteggia lesions in children. J Child Orthop. 2007; 1(4):237-42.

23. Wang MN, Chang WN. Chronic posttraumatic anterior dislocation of the radial head in children: thirteen cases treated by open reduction, ulnar osteotomy, and annular ligament reconstruction through a Boyd incision. J Orthop Trauma. 2006;20(1):1-5.

24. Oka K, Murase T, Moritomo H, Sugamoto K, Yoshikawa H. Morphologic evaluation of chronic radial head dislocation: three-dimensional and quantitative analyses. Clin Orthop. 2010;468(9):2410-8.

25. Best TN. Management of old unreduced Monteggia fracture dislocations of the elbow in children. J Pediatr Orthop. 1994;14(2):193-9.

26. David-West KS, Wilson NIL, Sherlock DA, Bennet GC. Missed Monteggia injuries. Injury. 2005;36(10):1206-9. 